\title{
Promoting electricity from renewable energy sources in emerging and developing countries - lessons learned from the $\mathbf{E U}$
}

\author{
R. Haas ${ }^{1}$, S. Busch ${ }^{1}$, G. Resch ${ }^{1}$, M. Ragwitz ${ }^{2} \&$ A. Held ${ }^{2}$ \\ ${ }^{I}$ Energy Economics Group, Vienna University of Technology, Austria \\ ${ }^{2}$ ISI, Fraunhoferinstitut, Karlsruhe, Germany
}

\begin{abstract}
Promoting renewable energy sources for electricity generation (RES-E) has high priority in many countries. The core objective of this paper is to identify proper regulatory promotion systems for RES-E in emerging and developing countries based on an evaluation of such systems in the EU over the period 2000-2008.

The major conclusions are: (i) Feed-in tariffs (FIT) will be a suitable instrument in emerging countries where a proper grid exists and where social acceptance of (low) transfer costs from electricity customers can be expected; this applies to countries like Brazil, China, India, Indonesia; (ii) for developing countries where solutions are mainly based on autonomous systems strategies has to focus on (international) support of investments; (iii) with respect to international trade of RES-E (e.g. from Africa to Europe) a more complex approach is required based mainly on two pillars: a royalty and a cross-border FIT.

Keywords: renewable electricity, promotion, emerging and developing countries.
\end{abstract}

\section{Introduction}

To increase the share of renewable energy sources for electricity generation (RES-E) has a high priority in the energy strategies of many countries. However, to facilitate a breakthrough for RES-E, a series of economic, institutional, political, legislative, social and environmental barriers has to be overcome. It is important to state that these barriers may vary considerably between industrialized emerging and developing (E\&D) countries. Of core relevance world-wide is currently the implementation of proper financial support systems. 
Whether trading-based (e.g. the recently announced Guarantee-of-Origin trade) or technology-specific instruments (like feed-in tariffs (FIT)) lead to preferable solutions for society is still under discussion, see, e.g., the discussion in Haas et al. 2011 [1].

This issue is discussed very controversially in industrialized countries like EU-27 and USA. However, it is even more controversial and complex if it addresses emerging and developing (E\&D) countries. In this context it also of interest that the European Commission puts strong focus on the aspect of International cooperation on promotion of RES-E., see [2].

Moreover with respect to international trade in recent months the idea of constructing large solar power plants, e.g. in Northern Africa, and transporting the electricity to e.g. Europe has attracted attention again. In this context a major question is, to what extent and in which form the population of the "host" country could benefit from such a project.

The core objective of this paper is to discuss the following three aspects of regulatory promotion systems for electricity from RES in emerging and developing countries based on the lessons learned from EU-countries: (i) What is in principle the favourable promotion scheme from the looking at the additional costs all customers finally have to pay? (ii) What is recommendable to emerging vs. developing countries? (iii) How must a comprehensive international regulatory framework and financial as well as electricity exchange framework look like to foster international cross-border investments in renewable electricity and trade?

\section{How promotion strategies work}

In this section first a survey on regulatory promotion strategies and their features is given. Of course, a specific programme put into practice may consist of a mix of different strategies. Next it is clarified what the core objectives of promotion strategies are and that with respect to every regulatory strategy an artificial market is created. How different types of promotion strategies work and what are important aspects of promotion strategies from customer's/the public's point-ofview is analysed at the end of the section.

The following analysis is based on the concept of static (and further-on dynamic) cost resource curves of RES (see, e.g., [3]). Fig. 1 depicts the typical profile of a stepped static cost curve taking into account that every location is slightly different from each other. Different sites are put into certain categories and then a stepped curve emerges. Moreover, as Fig. 1 shows these cost curves are associated with uncertainties. These uncertainties are the higher the more right we move in the diagram. We use these static (and further-on dynamic) cost resource curves to assess the over-all costs of different promotion schemes.

The core question is now how much money producers should receive in addition to the investment costs described in Fig. 1. Of course, investors in new RES-E generation plants should be compensated in a fair way but not by means of exaggerated profits. Hence, the major challenge for policy designers is to 


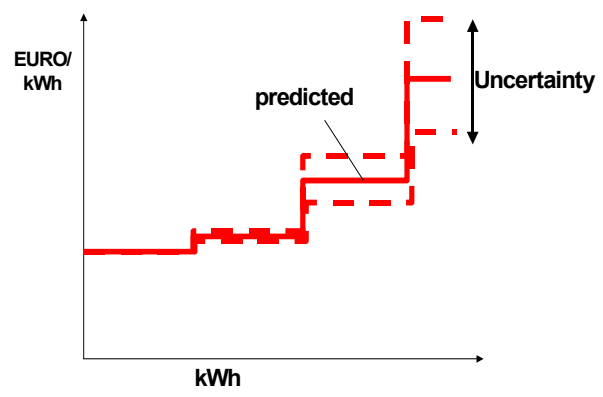

Figure 1: $\quad$ Stepped (discrete) static cost curve [3].

strike a reasonable balance between total generation costs and the producers' surplus (PS). The producer surplus is defined as the sum of the profits of all green electricity generators.

Figure 2 depicts the relationship between total generation costs and the producers' surplus (PS) for a FIT system with three different tariffs for three technologies. We can see a moderate PS which is - as the experience from some EU-countries shows - accepted by the investors. The total additional costs which finally have to be paid by the electricity customers - consist of the PS and the additional generation costs (costs above the market price of electricity).

Figure 3 shows the corresponding total costs for customers under a Tradable Green Certificate (TGC) system. A TGC-based quota system works as follows, see Fig. 3: A quota (= certain quantity or percentage of electricity to be guaranteed from renewable energy sources) is set by a government. The generators (producers), wholesalers, retailer or consumers (depending who is obligated in the electricity supply chain) are obligated to supply consume a certain percentage of electricity from renewable energy sources. At the date of

\section{(Premium) Feed-in tariffs}

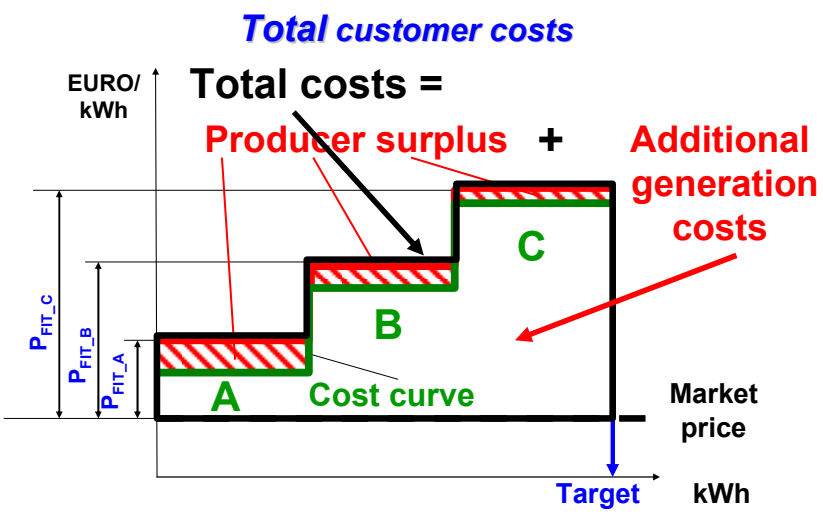

Figure 2: $\quad$ Total costs for customers under a feed-in tariff system [1]. 


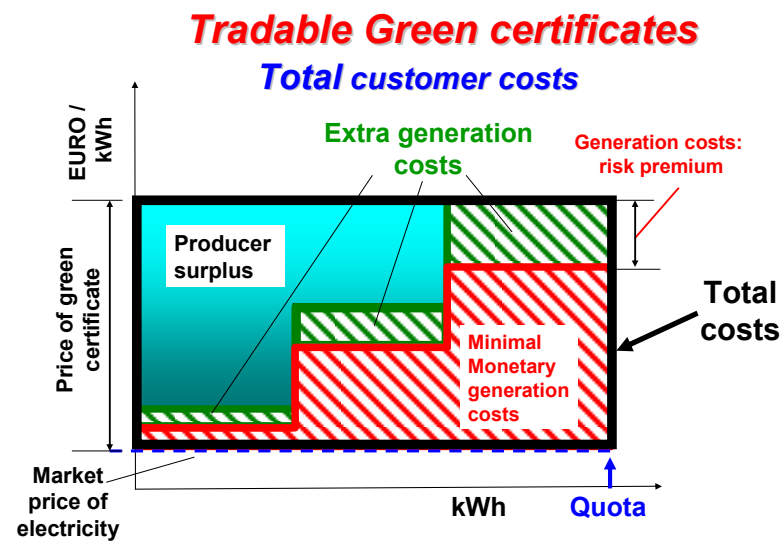

Figure 3: Total costs for customers under the Tradable Green Certificate system [1].

settlement, they have to submit the required number of certificates to demonstrate compliance. The total additional costs - which finally also in this case have to be paid by the electricity customers - encompass the whole black rectangle in Fig. 3.

From society's point-of-view it is of course important to minimise these additional costs (fees finally paid by households, commercial and industrial electricity customers) for the following reasons: the lower these additional costs are, the greater is the public acceptance and the larger will be the amount of additional electricity generated from RES per unit of public money.

So the most effective strategy must focus finally on the minimization of total transfer costs to ensure both, acceptance by customers and by investors. To minimise producer surplus (PS), a stepped promotion scheme that limits PS, see Fig. 2, reduces the resulting producer surplus correspondingly.

If we now compare the total costs in Fig. 2 and Fig. 3 we can clearly see that they are much higher in Fig. 3 and hence, for society it is of course more beneficial to implement a FIT (see also [4]).

\section{The success of promoting RES-E in the EU}

The success of European promotion strategies for RES-E is shown in Fig. 4. An almost exponential growth took place since the beginning of the 1990s. The major driver were the EC's directives for promoting RES-E ([2] and [5]). In different countries the efforts of the member states have led to continuous, albeit varying progress, building on their experiences gained and recommendations made by the commission.

Fig. 5 shows the latest effectiveness indicator for wind onshore relating the RES-E produced to the remaining potential. Compared to former editions one can observe that countries with quota systems have improved, while FIT 


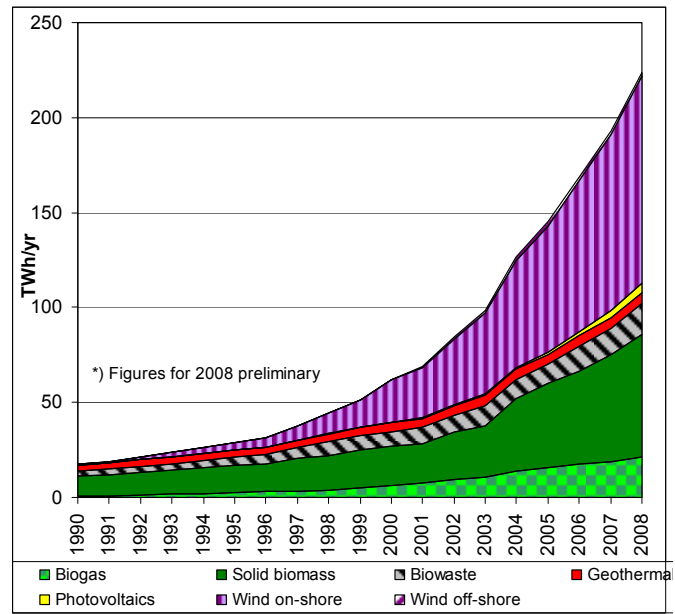

Figure 4: Development of "new" RES for electricity generation (Source: EUROSTAT).

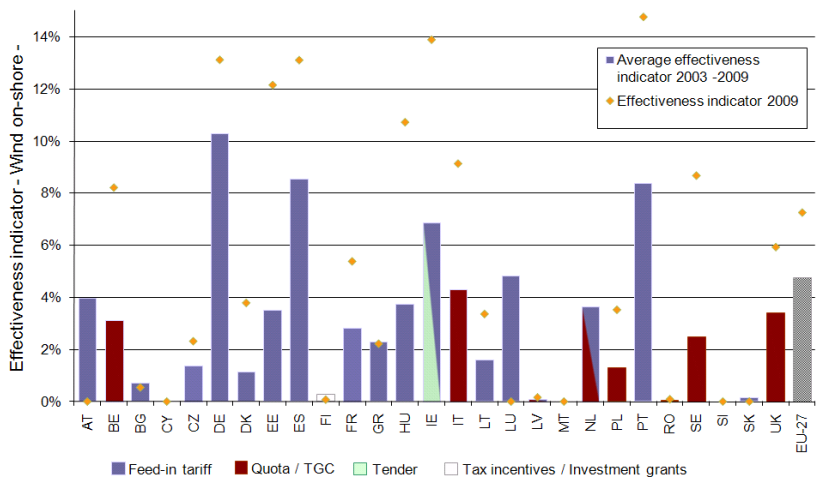

Figure 5: Effectiveness of promotion instruments for wind on-shore in the period 1998-2009 in EU-27 (Source: [6]).

countries still take the lead. Overall the experience with the support schemes has shown that depending on the instrument some "best practice" design criteria have emerged, which will be addressed below.

To identify the major country-specific lessons learned, next the relation between quantities deployed and the level of support is analysed for some trading and some FIT systems in recent years. It is often argued that the reason for higher capacities installed is a higher support level. Paradoxically, countries with highest support levels - Belgium and Italy for example - are among those with the lowest specific deployment (Figure 5). On the other hand, high FITs 
especially in Germany and Spain are often named as the main driver for investments especially in wind energy. However, the support level in these countries is not particularly high compared with other countries analysed here.

Currently in various European countries different strategies are in force. Next the relation between quantities deployed and the level of support is analysed for some trading and some FIT systems in recent years. It is often argued that the reason for higher capacities installed is a higher support level. And it is accepted that the resource endowments of RES-E vary from country to country.

Paradoxically, countries with highest support levels - Belgium and Italy for example, see Fig. 6 - are among those with the lowest specific deployment (Figure 5). On the other hand, high FITs especially in Germany and Spain are often named as the main driver for investments especially in wind energy. However, the support level in these countries is not particularly high compared with other countries analysed here, see Fig. 6.

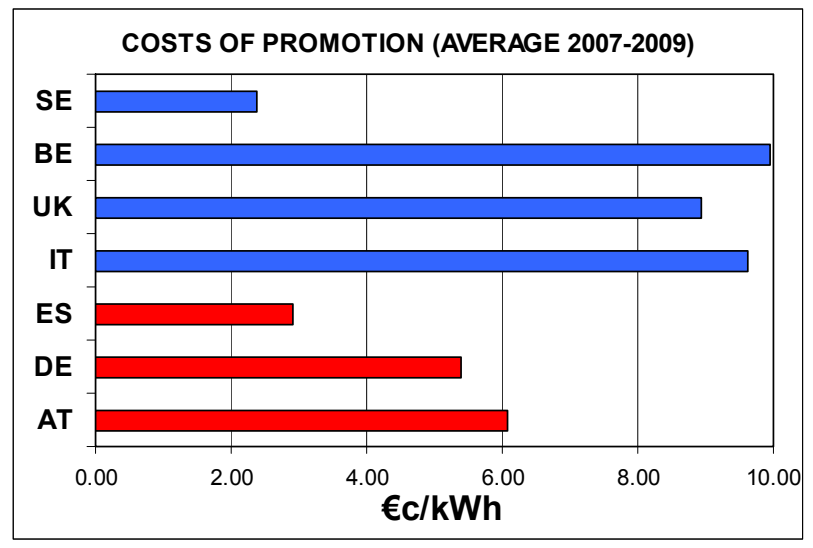

Figure 6: Costs of promotion programmes for electricity from RES (except Photovoltaics) in selected countries 2007-2009 (Source: own investigations).

\section{Lessons learned for emerging countries}

In an IEA study, the same methodology was extended to assess the effectiveness of RES support policies in OECD and BRICS countries (IEA 2008 [7]). The study concluded that the different countries show substantial diversity in the effectiveness of policies implemented to support the RET and that OECD-EU countries, which have overall a longer history of renewable energy support policies, feature among the countries with the highest policy effectiveness for all new renewable electricity generation technologies. This shows that a transfer of the lessons learned with EU RES-E support could add value to RES-E promotion in emerging countries. Exemplary this will be done here for two developing /emerging countries, China and Turkey. 
Firstly their currently implemented support instruments are revisited briefly. With the adoption of the Renewable Energy Law on January 1st 2006 China established for the first time a statutory framework for the development of renewable energy. Concerning the financial support of RES-E, two different instruments are foreseen, depending on the type of technology: Wind power projects are allocated to investors through competitive bidding. The government guarantees the successful bid price combined with an obligation to feed the power into the grid. Biomass electricity receives a guaranteed premium feed-in price in size of $0,25 \mathrm{Yuan} / \mathrm{kWh}$, decreasing by $2 \%$ yearly from $2010 \mathrm{on}$. Feed-in prices for PV systems are set by the government on a project-base, and mechanisms for other renewable energy technologies such as wavepower or geothermal electricity have to be established in the future.

Turkey introduced initially a FIT for the support of RES-E in May 2005. The tariff was slightly increased in May 2007 to a level of $50 € / \mathrm{MWh}$ to $55 € / \mathrm{MWh}$, which can neither be gone below nor exceeded. The tariff is determined by the Electricity Market Regulation Authority and is the previous year's wholesale price. In addition the national transmission company is obliged to provide grid connection for all RES-E projects. In general the Turkish support scheme is kept simple.

So what can the emerging countries learn from the EU? The experiences in Europe have shown, that especially at earlier stages of RET deployment FIT work best. Also the support instruments alone are not of high effectiveness if non-economic barriers like bureaucratic hurdles or grid connection issues are not solved. We have also seen that countries once they had found their appropriate support scheme have used the experiences gained to fine tune and gradually improve their schemes. This has led to increasing RES-E deployment and also formerly very uneffective countries could raise their effectiveness indicator.

Out of the experiences with the support schemes in the EU a list of "Best Practices" emerged that have either been introduced in the countries or have been recommended. Since both countries we have looked at in this article use FIT, and FIT is the most widespread instrument, we discuss some best practices in the following, that emerged from the experiences with RES-E promotion in the EU:

- RES-E support requires continuity and log term investment policy. Therefore FIT should be accompanied by long term targets and sufficiently long periods for which the tariff is guaranteed. A long term strategy for deploying significant amounts of RES-E generation has to build on fundamental $R \& D$ technology development which provides by means of proper technology transfer to E\&D countries successful implementation of projects. In this chain financing in different forms is a fundamental requirement, see Fig. 7.

- Technology specific tariff levels should be applied in order to reflect the varying electricity generation costs. The levels should be set so that the policy goals of a country can be reached and the most cost efficient RET at a particular location are deployed first. Stepped tariffs can be applied to reflect different power generation costs within the same technology. 


\section{LONG-TERM STRATEGY IDEVELOPMENT}

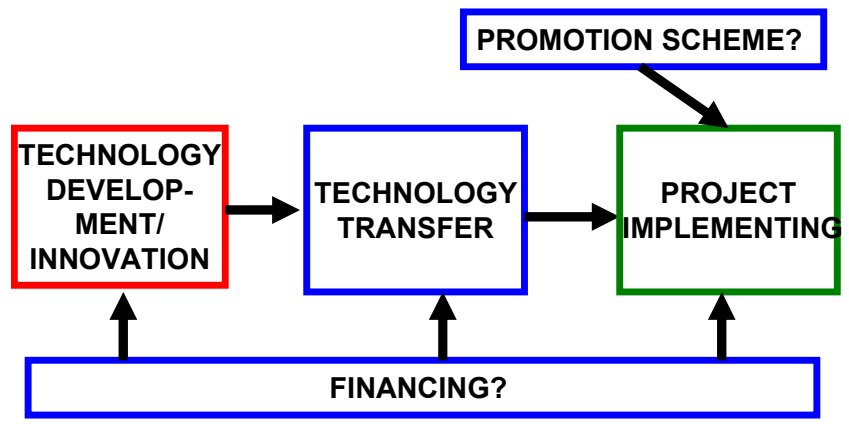

Figure 7: Financing in different forms for providing successful implementation of projects.

- RES-E support policies should consider market integration. In the case of FIT this could e.g. be reached through a bonus tariff. With the option to sell the electricity on the free market. Another important aspect in this context is a forecasting obligation.

- An annual tariff degression provides an incentive for cost reductions and technology improvements.

\section{An international framework for the transfer of electricity from developing countries}

A specific case of promoting RES-E is to generate and to import it from a third country. The most intensively discussed example currently is to produce electricity in the Sahara and to transport it to Europe.

This is arguable because renewable energy resources e.g. solar electricity are often situated in emerging or developing countries of the south. One of the major current examples in this context is the DESERTEC project. Within this project the intention is to produce solar electricity in the Sahara at lower costs and with higher full load hours than in Europe.

Aside from policy aspects a major challenge in such a project is to set up a framework where the host country (in the south) and the investor country (in the North) both benefit. Of course, this example can be transferred in principle to every case where a rich country invests in a less rich country to benefit from its resources.

Such a framework will in detail look much more sophisticated than just looking at investments and transmission of electricity. 
In the following we will identify proper regulatory promotion concepts for an international exchange of RES-E mainly between developing countries on the one side and between industrialized countries like the EU on the other side. In this context most important is to strike a socially and ecologically acceptable balance between local use and international trade. It also has to be considered that local use will be cheaper and energetically more efficient because of a lack of transport losses.

When setting up such an international framework we have to consider two major dimensions: The flow of money and the flow of electricity.

First we analyse the monetary issues. We have to differ between one-time initial up-front investments and the flow of money over the time the project is operated. With respect to up-front investments - see Fig. 8 - aside from the investment in the power plant also investments in the international transmission grid and the distribution grid of the host country - as a compensation for the acceptance of the deal by its population - has to be borne by the investor country (=target country of RES-E). Moreover, a one-time royalty - purchase of land area - must be considered.

\section{INITIAL UP-FRONT INVESTMENTS}

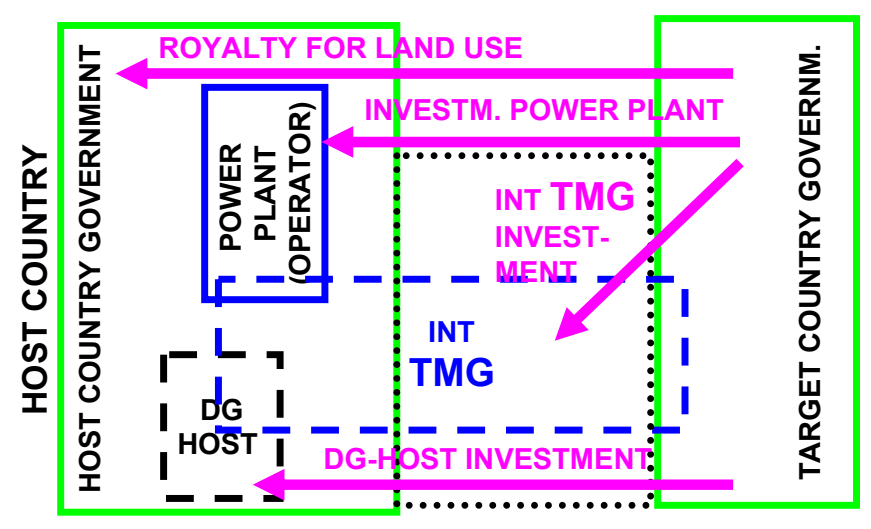

Figure 8: Initial up-front investments by target country of RES-E with electricity produced in the host country.

Regarding the flow of money during the operation of the power plant a more complex approach for the payments to the host country is required. It may consisting of a permanent payment to the hosts' government ("rent for land use"), a payment for the host country's government support of investments into the local distribution grid a cross-subsidization of a beneficial local electricity tariff, see Fig. 9. The revenues come from the international FIT. 


\section{INTERN. FLOW OF MONEY DURING OPERATION}

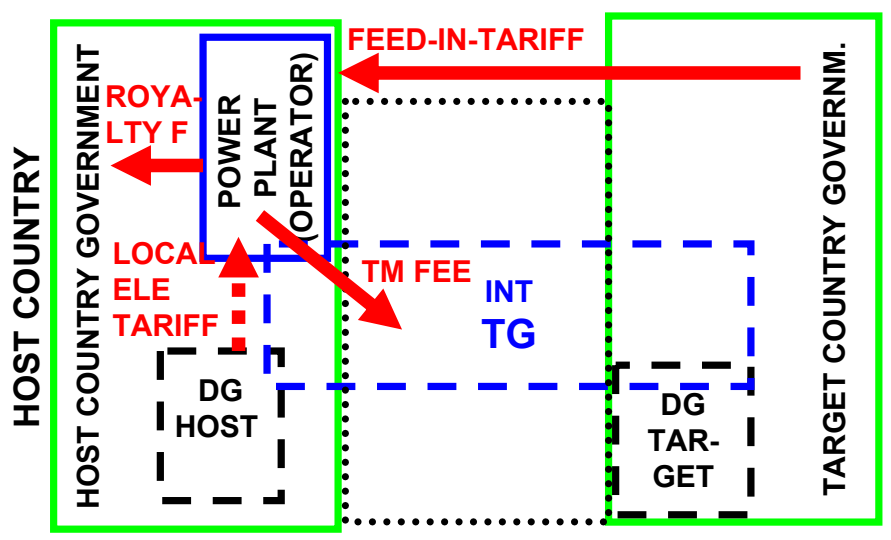

Figure 9: International flow of money between target country and host country for RES-E during the time of the operation of the plant for electricity produced in the host country.

Finally, given these financial boundary conditions the deal will only come about from the investor country's point-of-view if the following objective function leads to a positive outcome:

$$
\operatorname{MAX} \sum_{\mathrm{T}=0}^{\mathrm{LT}}\left(\mathrm{E}_{\text {IMP }} * \text { FIT }\right)-\mathbf{C C}\left(\mathrm{E}_{\text {IMP }}\right)_{t}-\mathrm{C}_{\text {O\&M }}\left(\mathrm{E}_{\text {IMP }}\right)_{\mathrm{t}}
$$

with:

E $_{\text {IMP }} \quad$ Electricity imported e.g. by the EU $(\mathrm{kWh})$.

FIT international Feed-in tariff (EUR/kWh).

$\mathbf{C C}\left(\left(\mathbf{E}_{\mathbf{I M P}}\right)_{\mathbf{t}} \quad\right.$ Capital costs of all investment related to imported electricity (see Fig. 8) (EUR).

$\mathbf{C}_{\text {O\&M }}\left(\mathbf{E}_{\text {IMP }}\right)_{\mathbf{t}}$ Operation, maintenance and other running costs of imported electricity (see Fig. 9) (EUR).

Regarding the flow of electricity, we have to consider that a certain amount is consumed in the host country and that there are some transmission and distribution losses (see Fig. 10). 


\section{INTERN. FLOW OF ELECTRICITY}

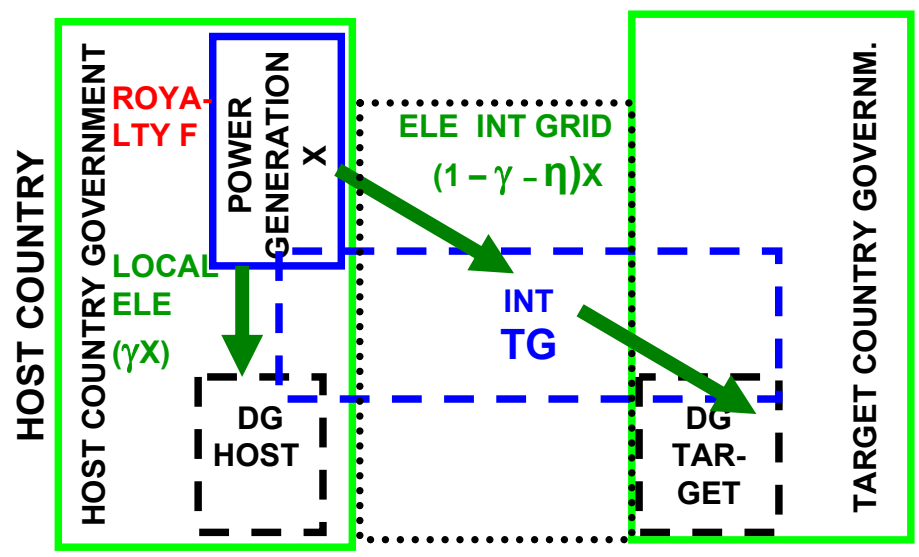

Figure 10: International flow of electricity from RES between target country and host country with electricity produced in the host country.

\section{Conclusions}

The major conclusions of this analysis are:

(i) FIT and premium systems in European countries have proven to be of superior effectiveness and efficiency for promoting RES-E compared to TGC systems; Moreover, in these countries also evidence has been provided that RESE investors accept this approach and provide the necessary corresponding investments; (ii) Hence, FIT will be a proper instruments in emerging countries where a proper grid exists and where a social acceptance of (low) transfer costs from the electricity customers can be expected; This applies to countries like Brazil, China, India, Indonesia ... (iii) for developing countries where solutions are mainly focusing on islanding autonomous stand-alone solutions are based only strategies focusing on (international) support of investments are feasible; (iv) With respect to extended international electricity trade (e.g. from the Sahara to Europe) a more complex approach is required: It has to differ between initial investments and flow of money during the operation of the project. And it has to build on two major pillars: different types of royalties paid to the host country and an international cross-border FIT.

\section{References}

[1] Haas, R., G. Resch, Christian Panzer, Sebastian Busch, Mario Ragwitz, Anne Held: Efficiency and effectiveness of promotion systems for electricity 
generation from renewable energy sources - Lessons from EU countries, ENERGY-The international journal 2011 (forthcoming).

[2] European Parliament and Council. (2008). Directive of the European Parliament and of the Council on the promotion of the use of energy from renewable sources of, Brussels, COM 2008 (30) Final.

[3] Haas, R., Eichhammer, W., Huber, C., Langniss, O., Lorenzoni, A., Madlener, R., Menanteau, P., Morthorst, P.-E., Martins, A., Oniszk, A. (2004): How to promote renewable energy systems successfully and effectively. Energy Policy, 32(6): 833-839.

[4] Held, A., Haas, R., Ragwitz, M. 2006. On the success of policy strategies for the promotion of electricity from renewable energy sources in the EU. Energy \& Environment, 17 (6), p. 849-868.

[5] European Parliament and Council (2001): Directive of the European Parliament and of the Council on the promotion of electricity produced from renewable energy sources in the internal electricity market, Directive 2001/77/EC - 27 September 2001, Brussels.

[6] Ragwitz, M. 2010. Effective and efficient long-term oriented RE support policies, Presentation held at International Energy Agency Renewable Energy Working Party's Workshop "Renewables, from Cinderella options to mainstream energy solution", March 15th 2010, Paris

[7] International Energy Agency. 2008. Deploying Renewables - Principles for Effective Policies, Paris, France 